Johnson County Community College ScholarSpace@ JCCC

2-7-2013

\title{
Studies of Economic Development
}

Paul Kim

Johnson County Community College, paulkim@jccc.edu

Follow this and additional works at: http://scholarspace.jccc.edu/econpapers

Part of the Economics Commons

\section{Recommended Citation}

Kim, Paul, "Studies of Economic Development" (2013). Economics Papers and Presentations. 3.

http://scholarspace.jccc.edu/econpapers/3

This Article is brought to you for free and open access by the Business at ScholarSpace @ JCCC. It has been accepted for inclusion in Economics Papers and Presentations by an authorized administrator of ScholarSpace @ JCCC. For more information, please contact bbaile14@jccc.edu. 
STUDIES OF ECONOMIC DEVELOPMENT, revised-2/7/2013

\section{Definition of Economic Growth}

Economic growth is achieved for the purpose of the raising living standard of a nation and is measured by the rate of an increase in real GDP (or real GDP per capita). Thus, economic growth has to do the production and increase in production of goods and service of a nation. This paper explains the major source of economic growth that is found in (1) an increase in labor productivity through (a) building human capital or simply called - investing in education, (b) capital formation and (c) advancement of technology as well as (d) the mobilization unemployed (or disguised) workers from rural areas into the industrial sector, and (2) the increase in labor inputs or hours (as well as an increase in the number of resources) or simply called a variable (e), and (3) removing of waste or simply called (f).

The unique feature of the above new model is the inclusion of (f), which happen to be negative number such as $-2 \%$ or $-3 \%$, intended to be subtracted from a nation's recorded growth rate later, which is intended to readjust the typical growth rate computed. The portion of the output produced, which is imputed in the final growth rate, and some of which are not consumed nor used or are not paid by the people who consume it, is subtracted from the final growth rate in our model as shown in (f). However, the difficulty of our model presented above is the computation of (3) since what we call waste can be found or computed only in the future or (several years) later after the final growth rate is computed. We will discuss it later in this paper. Note that the traditional economic growth rate is computed based on (1) and (2): Labor productivity growth rate and the growth rate of labor inputs. 
The most popular method of achieving the rapid economic growth of a developing nation especially in Asia like China is found historically in (d) (in conjunction with (a)) but needed to be adjusted by (f) according our model, while an advanced nation's economic growth strategies such as that of the U.S., mainly focus on (b) and (c): Labor productivity growth through technological advancement and capital formation (while maintaining (a)).

Thus when a nation's path of economic growth evolves from the former to the latter as noted above, some nation's stages are into lie between the above two stages. Note that the economic growth achieved through (f) is an one time chance since rural area disguised unemployment will be exhausted at some point.

Therefore the major source of the rapid economic development of a developing nation is found in the mobilization of the nation's labor force from less, and or unproductive sector (rural area) to a productive sector (industrial sector), which is identified in (d), which was suggested by W.A. Lewis. (Sometimes this includes labor force participation factor.) This method of achieving the rapid economic development is often facilitated and induced by the government projects (often propelled by exports). What is new to the above model presented here is that the growth rate achieved had to be readjusted by (f) or re-computed based on (f), especially when the government involvement is extensive, which had been in effect in many Asian nations, most recently in China.

It is said that technology is more important than the capital accumulation because even a nation accumulate capital stock if it fail to utilize capital due to the lack of technology, the production of capital goods end in vain. But our model propose in (f) is different from the above notion. The production of capital goods (as well as consumption goods) end in vain, 
although it is recorded in GDP figure, because the production of such capital goods are originally motivated heavily in increasing GDP and employment so as to facilitate (d). But it fails in later years to find the people who appreciate (or value highly) and consume them or use them. This is the reason we have included (f) in our model.

The overwhelming desire to facilitate (d), thus taking aggressive action especially by a government to increase the economic growth rate, is the major reason why the excessive capital goods produced ends in vain not necessary the lack of technology, which led us to include (f) in our model. 